\title{
Predictive processing and foundationalism about perception
}

\author{
Harmen Ghijsen ${ }^{1}$
}

Received: 30 August 2017 / Accepted: 1 February 2018 / Published online: 10 February 2018

(C) The Author(s) 2018

\begin{abstract}
Predictive processing accounts of perception (PP) assume that perception does not work in a purely bottom-up fashion but also uses acquired knowledge to make top-down predictions about the incoming sensory signals. This provides a challenge for foundationalist accounts of perception according to which perceptual beliefs are epistemically basic, that is, epistemically independent from other beliefs. If prior beliefs rationally influence which perceptual beliefs we come to accept, then foundationalism about perception appears untenable. I review several ways in which foundationalism might be reconciled with PP from both an internalist and externalist perspective, and argue that an externalist foundationalism provides the best match with PP.
\end{abstract}

Keywords Foundationalism · Justification - Predictive processing - Epistemic downgrade $\cdot$ Dogmatism $\cdot$ Inferentialist reliabilism

\section{Introduction}

In epistemological theories about perceptual justification, several versions of foundationalism have become increasingly popular. On internalist versions of the view, perceptual experiences, or perceptual seemings, provide immediate prima facie justification for basic perceptual beliefs, whereas on externalist versions basic perceptual

This work is part of the research programme "Should we trust our own eyes? Epistemic challenges from cognitive penetration and implicit bias" with Project Number 275-20-056, which is financed by the Netherlands Organisation for Scientific Research (NWO).

$凶$ Harmen Ghijsen

h.ghijsen@ftr.ru.nl

1 Faculty of Philosophy, Theology and Religious Studies, Radboud University, Erasmusplein 1, PO Box 9103, 6500 HD Nijmegen, The Netherlands 
beliefs derive their immediate justification from being the output of a properly functioning or reliable process. ${ }^{1}$ At the same time, predictive processing accounts of perception (PP) have become increasingly popular in philosophy of mind, according to which perceptual experiences and beliefs arise as the result of the brain's attempt at predicting sensory input on the basis of a large amount of stored knowledge. Given this latter development, one might wonder whether epistemological theories about the structure of justification do not presuppose an outdated conception of the mind. If all of our perceptual beliefs only arise on the basis of acquired knowledge about the world, can they still be epistemically basic as foundationalists maintain? It is the main goal of this paper to review several ways in which foundationalists might respond to this challenge. As a subsidiary aim, I intend to make plausible that an externalist foundationalism will provide the best match with PP.

The first and second sections will give brief introductions of respectively foundationalism about perception and a predictive processing account of perception. The third section reviews several ways of combining PP with an internalist foundationalist account of perception, beginning with a strong view according to which perceptual experience provides immediate prima facie justification for belief despite what happens at the subpersonal level (Fumerton 2013; Huemer 2013), and ending with a weak Siegelian view (Siegel 2012, 2013, 2017b) according to which even subpersonal priors are relevant for perceptual justification. Although the strong view clearly remains foundationalist, PP appears to undercut its motivation for considering perceptual experience as the unjustified justifier of perceptual belief. The weak view, in contrast, can ascribe a rational role to the background knowledge posited by PP, but has difficulties in upholding its foundationalist roots. Section four reviews an externalist foundationalism that sharply distinguishes between personal-level beliefs and subpersonal assumptions and claims that personal-level beliefs can only be evidentially based on other personal-level beliefs (Lyons 2009, 2016a). Although this plausibly entails that perceptual beliefs cannot be evidentially based on the stored knowledge posited by PP, the theory appears to lack a principled motivation for its different epistemic treatment of personal-level beliefs and subpersonal assumptions. I end section four by outlining an alternative externalist account according to which PP's stored knowledge could be considered as an evidential basis that is itself justified because of external factors such as reliability. This would prevent positing an unprincipled distinction between personal-level beliefs and subpersonal assumptions and still allow a foundationalist take on $\mathrm{PP}$ - albeit one where the epistemic foundation surprisingly consists of a rather malleable set of subpersonal assumptions.

\section{Foundationalism about perception}

According to contemporary foundationalists about perception, perceptual beliefs are epistemically basic: their prima facie justification does not epistemically depend on any

\footnotetext{
${ }^{1}$ See Tucker (2013b) for a collection of articles on 'seemings' theories of perceptual justification, and see Lyons (2009) for a process reliabilism that makes the connection to foundationalism explicit.
} 
further beliefs. Immediately note three things about this characterization of basicality. ${ }^{2}$ First, being epistemically basic does not imply that the belief is infallible, incorrigible or indubitable. Basic beliefs could be easily rejected in the light of additional evidence, they merely provide a starting point for our inquiries. Second, being epistemically basic leaves open whether beliefs are ultima facie or even prima facie justified. What matters to epistemic basicality is the absence of epistemic dependence on further beliefs, not the presence of what actually makes basic beliefs prima facie justified. Third, although epistemically basic beliefs should not epistemically depend on further beliefs, they might still depend on those further beliefs in different ways. For instance, to believe that the color of a certain object is red, I might first have to know general things about different colors and the way these colors look under different lighting conditions. Perhaps some of this knowledge should be construed as knowledge-that rather than knowledge-how. If so, this still does not imply that my belief that this object is red epistemically depends on the general knowledge I have about colors. The general knowledge might just count as an enabling condition to have beliefs about colors in the first place. At the very least, it requires further argument to show that there is an epistemic rather than mere conceptual or counterfactual dependence at work here.

The relevant type of epistemic dependence on beliefs that is at work in the foundationalist theory appears to be one that is closely related to the notion of basing: if a belief is based on further beliefs, then the belief epistemically depends on those further beliefs and is not epistemically basic. We can distinguish this evidential dependence from a weaker form of epistemic dependence between beliefs, where a belief weakly epistemically depends on another if it would not be justified were the other belief unjustified (Lyons 2016a). The latter form of dependence can be present even if there is no evidential dependence; e.g., my belief that there is a chair over there weakly epistemically depends on my belief that there is a physical object over there (if the latter were unjustified, so would the former) but it's implausible that it is also based on the latter belief. ${ }^{3}$

Which precise beliefs will count as perceptual beliefs, and what it is in virtue of which these perceptual beliefs are justified, will differ on different versions of the above foundationalism. For instance, on a popular variety of internalist foundationalism about perception, one might claim that perceptual beliefs are those that are immediately based on perceptual experiences, and that they are prima facie justified in virtue of the content and phenomenology of the perceptual experiences on which they are based. ${ }^{4}$ In contrast, on an externalist foundationalism about perception, one could claim that perceptual beliefs are those that are the output of a perceptual system, and that they derive their prima facie justification from being the output of a reliable

\footnotetext{
2 This characterization of basic beliefs follows the one provided in Lyons (2009, p. 14).

${ }^{3}$ Note that it's open to foundationalists to also allow other relations of epistemic dependence besides evidential dependence to play a significant role in their theory. For instance, externalist foundationalists will typically hold that some beliefs can be non-evidentially justified by being the output of a reliable process.

${ }^{4}$ See, for instance, dogmatists about perception for such a view (Pryor 2000; Huemer 2001; Tucker 2010, 2013b; Chudnoff 2011).
} 
belief-forming process. ${ }^{5}$ The crucial difference between these two views is the role of conscious experience: where such experience plays a necessary role for justification on an internalist foundationalism, an externalist foundationalism can allow beliefs to be justified even in the absence of any experience. ${ }^{6}$

What reasons are there for upholding foundationalism about perception? First, it accords well with the phenomenology of perception. When we form our perceptual beliefs we are usually not aware of any inference on the basis of our current experience and additional background beliefs. We usually just find ourselves immediately believing things about our environment. However, this phenomenological fact is, at best, a defeasible reason in favor of foundationalism about perception. That we are not aware of inferring our perceptual beliefs from other beliefs does not imply that those perceptual beliefs are, in fact, not inferred from other beliefs. Perhaps such inference can simply take place unconsciously, thereby making perceptual beliefs non-basic. In other words, even though perceptual beliefs are phenomenologically basic, they need not be epistemically basic.

A stronger reason for foundationalism about perception is related to the regress problem. If all beliefs can only be justified if they are supported by further justified beliefs, then those justified beliefs must themselves also be supported by further justified beliefs, and so on, leading to an infinite regress of beliefs. Note that, on this conception of justification, it will not help to allow that the beliefs at the beginning of the justificatory chain can also help to support beliefs at the end of the chain: if justification only arises from being supported by beliefs that are themselves justified, then even a circular structure of support will not provide one with a first amount of justification to transfer. The obvious way out of this regress problem is to change the conception of justification at stake: some beliefs, i.e., epistemically basic beliefs, can also be justified without support from further justified beliefs. Again, the way in which these basic beliefs would then be justified could be cashed out in several ways; one could hold that they are non-evidentially justified by simply being the output of a reliable process, or one could hold that they are evidentially justified by being supported by conscious experiences that are themselves neither justified nor unjustified. ${ }^{7}$ Note that it's crucial that these conscious experiences need not themselves be justified, as the regress would then simply continue on by asking where this justification in turn would stem from.

Of course one could answer the regress problem differently, but these different answers appear less plausible for the case of perception. Take, for instance, a coherentist answer, which holds that the justification for a belief emerges in virtue of being a member of a coherent set of mutually supporting beliefs (or a member of a coherent set of mutually supporting beliefs and experiences on a more liberal version). ${ }^{8}$

\footnotetext{
5 See Lyons (2009) for this view.

6 To keep things manageable, I'm leaving out hybrid internalist-externalist versions such as that of Alston (1988) that could be taken to hold that justified perceptual beliefs require conscious experiences that reliably indicate those beliefs. Nevertheless, such versions would also suffer from the problems outlined in Sect. 3.1.

7 See Lyons (2009) and Ghijsen (2016a) for more on the difference between being evidentially and nonevidentially justified.

8 See, e.g., BonJour (1985) for a well-known account, and Kvanvig (1995) for a more liberal version.
} 
Such an answer would severely underestimate the epistemic force of perception, as it would always make it possible to simply ignore whatever one perceived by adding the belief that one was hallucinating. Although one could incorporate the epistemic force of perception into one's coherentism by requiring that one's belief-system contains beliefs about the importance of one's perceptual beliefs (BonJour 1985), this would go against the idea that justification simply emerges from coherence, and it would also create difficulties for agents that lack the intellectual sophistication to have higher-order beliefs of the envisaged sort.

Another answer to the regress problem, provided by infinitism, would hold that the property of justification is again not transferred from a basic belief to a further belief, but instead emerges from an infinite chain of reasons. ${ }^{9}$ On this account justification requires that there is a reason available for every justified belief, and for all of these reasons there need to be further reasons available, and so on. What's more, these reasons cannot be used to support themselves: circular reason-structures are not allowed. Applied to the case of perception, the account again appears less plausible than a foundationalist one. As long as there is no reason not to trust the deliverances of one's senses, we simply do not require an infinite chain of reasons to justifiably believe whatever one perceives. Of course it is always possible to question whether what one perceives is actually the case, just as it is possible to then question the reasons one could give for believing that what one perceives is actually the case, but the fact that one can always ask for more reasons does not show that these reasons are really doing any work in the original justification of the perceptual belief.

When it comes to perception, the foundationalist view thus appears to give the most plausible answer to the regress problem: it accommodates the inherent epistemic force that comes from perception, and is in line with what we require from agents who have justified perceptual beliefs. The next section will attempt to put pressure on this foundationalist view by exploring a challenge that arises from the idea that perception is crucially connected to top-down prediction.

\section{The challenge from predictive processing}

According to Predictive Processing (PP) accounts of perception, perception is not a purely bottom-up process that constructs a representation of the environment on the basis of retinal input, but instead involves a top-down process which attempts to predict sensory input on the basis of a hierarchical generative model. I will here follow Clark (2013, 2016) and Hohwy (2013) in their presentation of the basics of PP, although there are many different variations of PP and the way it is implemented in the brain. Note further that, even though we will here only be concerned with the PP account of perception, one of the motivations for PP comes from its surprising ability to also explain action in terms of predictive processing [indeed, sometimes all of cognition is portrayed as intrinsically related to predictive processing (Hohwy 2013)].

\footnotetext{
${ }^{9}$ See Klein (1999). See Peijnenburg and Atkinson (2013) for a more detailed account of how justification could emerge from an infinite chain of reasons.
} 
Let's start by looking at the precise way in which sensory input is predicted according to PP. Predictions take place at several levels in a hierarchical setting. Each level in the hierarchy attempts to predict the state of the level below, and the lowest level bottoms out in the sensory signal. Lower levels in the hierarchy correspond to faster time-scale regularities (such as how light is being reflected by a moving object) and higher levels to slower time scale regularities (from mid-level regularities concerning what objects there are in front of us to even higher-level regularities concerning what practices we are currently engaged in). The higher-level predictions constrain and inform lower-level predictions in the sense that if I know that I am currently playing tennis, then I can already predict which type of object is currently moving towards me (i.e., the tennis ball). These predictions are then compared to the actual state of the level that is being predicted, and the computed prediction errors are used as feedback to sharpen or change the predictions at the higher level. In this way prediction errors are in principle able to influence predictions all the way up to the highest level, while predictions at the highest level also inform and constrain predictions at lower levels. In the end, to find the hypothesis that fits the world best, all the sensory system has to do is simply minimize prediction error. ${ }^{10}$

However, there is more to the story. In some circumstances one should expect a larger amount of prediction error than others. For instance, if you are trying to find your way at night in a badly lit environment, then the sensory input signal can be expected to contain more noise than when you are walking around in clear daylight. Similarly, if you are trying to hear what your friend is saying at a party, then you can also expect more noise in the sensory signal than when you are listening to a speaker in a lecture series. In terms of prediction error this means that in some circumstances even the best hypotheses about the world will deliver relatively large prediction errors due to noise in the sensory signal. In contrast, there can be other circumstances where similarly large prediction errors are a sign that one should alter one's predictions. So the perceptual system has to do more than simply compute the prediction errors at all of the levels in hierarchy, it also has to determine the extent to which these prediction errors are due to imprecise and noisy sensory signals. In contexts where the sensory signal is impoverished, prediction errors can then be suppressed without leading to changes in predictions. In contexts where the sensory signal is very precise, prediction errors can be taken seriously and thereby lead to changes in predictions.

So far I've said little about the way in which the predictions at the several levels in the hierarchy are made. This is generally thought to occur in Bayesian fashion: by taking into account how well a certain hypothesis is able to predict the sensory evidence (its likelihood), and how probable that hypothesis is to begin with (its prior probability), the posterior probability of the hypothesis given the sensory evidence can be calculated. The hypothesis with, for instance, the highest posterior probability can then be selected to determine perceptual content (although one could also expect the posterior to be weighted with expected utility). Note again that the generation of hypotheses goes on at all levels of the hierarchy, and that all these levels simultaneously influence this generation. For instance, at a higher level in the hierarchy certain hypotheses about

10 See Friston $(2009,2010)$ for more on the relation between minimizing prediction error and the more encompassing free-energy principle. 
the world around us (e.g., that objects have a uniform color) will have high priors, which constrain the hypotheses arrived at in lower levels (e.g., that the wall has the same color but is illuminated differently across its surface). On the other hand, high prediction errors at lower levels can also lead to changes in the priors of hypotheses at higher levels. It is this form of empirical updating of priors which makes sure that one's hypotheses are also shaped by the way the world actually is.

If PP is correct, then it seems the core tenet of foundationalism about perception, i.e., that perceptual beliefs are epistemically basic, is in trouble. After all, according to PP perceptual beliefs are the outcome of a process that takes into account almost everything that one has learned from previous experiences. Not only is a massive amount of context information used to predict and thereby influence perceptual processing, context is also used to determine to what extent the outcome of this perceptual processing should be driven by prior expectations or sensory input by altering the weight of prediction errors depending on their precision. What's more, the process that is involved appears to be constituted by a rational Bayesian form of reasoning, so it does not appear to be a stretch to call one's perceptual beliefs genuinely epistemically dependent on what one learned from previous experience. In what sense could such perceptual beliefs then still be taken as epistemically basic, as foundationalism about perception maintains? The following sections will evaluate two responses to this challenge, the first from the perspective of an internalist foundationalism, and the second from the perspective of an externalist foundationalism.

\section{Internalist foundationalist answers}

\subsection{Strong internalist foundationalism}

Recall that on an internalist foundationalism about perception, perceptual beliefs do not epistemically depend on other beliefs for their prima facie justification, but instead depend on being properly based on perceptual experience. A strong version of such a view holds that the justification stemming from perceptual experience is simply independent from whatever processes are involved in giving rise to this experience (Huemer 2013; Fumerton 2013). Even if the process leading to perceptual experience is along the lines sketched by PP, then this still does not make the beliefs based on this experience any less basic.

One might doubt whether such a strong view is really tenable. It seems to allow for cases where unjustified beliefs give rise to perceptual experiences which could then justify those previously unjustified beliefs (so-called bad cases of cognitive penetration) (Siegel 2012). For instance, suppose that Jill has the unjustified belief that Jack is angry. If this belief is capable of actually making Jack look angry, then the previously unjustified belief would suddenly become justified just because it is now also supported by a perceptual experience that was itself generated by the unjustified belief. This way of arriving at justified beliefs simply appears unacceptable, yet it is allowed by the type of strong internalist foundationalism that is under consideration. Sometimes this is even portrayed as a virtue of the theory: after all, if you really experienced Jack as angry, what else could you believe but that Jack is angry? Unfortunately, 
this line of response does not do much to alleviate the previous worries: even if it is rational to believe that Jack is angry in response to your experience, this does not entail that the belief is also epistemically justified. ${ }^{11}$

Note, though, that PP does not entail that the previous sort of scenario is actually possible. Nowhere in its account of perception does PP explicitly mention beliefs. The priors, likelihoods and competing hypotheses could all be subpersonal states rather than full-fledged beliefs. ${ }^{12}$ This accords with the fact that we might not readily assent to the sort of information that is used in the hierarchical model proposed by PP [e.g., that lighting usually stems from above, that stimuli will be repeated, that slower motions are more likely than faster ones (Seriés and Seitz 2013)]. If there are no beliefs involved in the process leading to perceptual experience, then PP clearly does not license the previous kind of pernicious circular inferential structure where an unjustified belief that $p$ leads to a perceptual experience that $p$, which in turn justifies the belief that $p$. In fact, given that PP upholds the idea that perceptual experience is the result of a type of Bayesian abductive reasoning, the whole worry about this type of circularity does not appear to get off the ground even if one assumes that priors are also a type of belief. The content of the relevant priors does not simply become the content of perceptual experience; the content of the priors is used to probabilistically determine what content is the best explanation of the received sensory signal. ${ }^{13}$

Combining PP with a strong internalist foundationalism thus does not immediately lead to counterintuitive results. However, the core idea of this foundationalism is still that perceptual experience is a source of justification precisely because it is not itself justified or unjustified, or rational or irrational. Perceptual experience is supposed to be the a-rational given that is at the start of a chain of justification, it is not supposed to be itself based on further evidence. If it were so based, then one of the key motivations for foundationalism, i.e., its providing a satisfying answer to the regress problem, would be undercut. Experience would no longer provide a starting point for justification but would itself derive its justification from further evidence, for which the same question of justification would then again arise.

If $\mathrm{PP}$ is correct, though, then it is no longer clear that we should not view experience itself as the result of an inferential process that can be normatively evaluated, and thereby as an entity that can be justified or unjustified, or at least rationally evaluated. For instance, if priors are not updated in the light of new evidence, the experiences they give rise to could be taken as unjustified, or as epistemically improper. The challenge

\footnotetext{
11 See Huemer (2013) for the line of response, and see, e.g., Jackson (2011), Tucker (2013a), Markie (2013), and McGrath (2013) for the rejoinder.

12 Macpherson (2017) argues on this basis that it is not at all clear whether predictive processing entails cognitive penetration. However, this is tricky territory, as in most purported cases of cognitive penetration it will be difficult to specify whether any specific belief is cognitively penetrating perception anyway. See Lyons (2011, p. 302) and Varga (2017, pp. 6-7) for more on this.

13 Note that Siegel (2017b, pp. 116-117) presents a different circularity problem for this Bayesian take on perceptual experience: on the basis of one's perceptual experience one might consciously strengthen one's credence in the very hypothesis that was selected to determine the content of that experience. In this case there would be a bad type of double counting: first a posterior is calculated subpersonally, correctly taking into account likelihoods and priors, and then that posterior is strengthened even more on the basis of the very conscious experience that the posterior has supposedly determined. However, this worry only gets off the ground if this form of conscious strengthening is really possible, something on which PP is silent.
} 
for a strong internalist foundationalism thus consists in explaining why subpersonal inferential processes would be irrelevant in determining whether a subject's perceptual experiences, and thereby the subject's perceptual beliefs, are justified.

Now, one answer to this challenge would have it that the kind of subpersonal inferential processes at work in PP are not genuine inferential processes at all. At best, the Bayesian story provided by PP presents us with a model of what is going on subpersonally, but it is not a realistic description of the processes that actually take place. In response, one could point out that the same is true for many cases that would normally be taken as genuine cases of inference. For instance, in response to seeing that it's raining, I might infer that I should take my umbrella with me when I go outside. We could describe this inferential process by listing all the premises that would together imply that I should take my umbrella with me (e.g., that if it's raining, I will get wet; that I don't want to get wet; that an umbrella would prevent me from getting wet; etc.), but of course it's implausible that this would provide a realistic description of the processes that are actually going on subpersonally. So what a strong internalist foundationalism would have to do is show that the notion of inference at play in PP is radically different from the notion of inference that is operative in many daily cases of reasoning.

One might think that this explanatory burden could be met. After all, a crucial difference between the inferences posited by PP and those in daily cases of reasoning lies in their supposed conclusions: in daily reasoning the conclusion is a belief, whereas the inferences posited by PP result in experience. This might lead one to doubt that PP should be understood as being about genuine inferences from premises to conclusions at all. However, this reasoning assumes that there is a crucial distinction between experience and belief that would make only the latter appropriate for being a genuine result of inference. And, as long as one takes PP seriously, it's not clear that this distinction can be upheld. After all, we're already supposing that perceptual experiences have representational content that is calculated in Bayesian fashion, so there seems to be no obstacle to supposing that this content is a genuine conclusion based on premises constituted by priors and likelihoods in a way that we're familiar with. ${ }^{14}$ This representational content might not be sufficient to account for all aspects of perceptual experience-for one, it seems to leave out the phenomenal aspect of experience-but it does seem sufficient to account for the possibility of genuine inference. ${ }^{15}$

Another type of answer to the challenge would cite the inaccessibility of subpersonal processes as the explanation of their irrelevance to justification. On the assumption that only accessible entities are relevant for justification, only experiences would come out as being relevant for the justification of perceptual beliefs. Now, this answer seems unsatisfying to me on the grounds that many inaccessible things appear to have an impact on justification. ${ }^{16}$ For instance, I might now apparently remember

\footnotetext{
14 But see Bruineberg et al. (2016) for a radically different content-free version of PP, though this is so different that one might even hesitate to still call it a version of PP_it's certainly not a version of PP as I have described it.

15 Also see Siegel (2017b) for more on the relevant notion of inference at play, and more on possible objections to an experience's having a rational standing in virtue of its nature as experience.

16 Also see Jackson (2011) for this line of thought.
} 
that Barcelona is the capital of Spain, having completely forgotten that I had no good grounds to believe this in the first place. Even though I can now only access a 'memorial seeming' which supports that Barcelona is the capital of Spain, my belief is still unjustified. It should not become justified merely because I have forgotten the fact that I formed the belief without any good grounds. Similarly for perceptual experience: if my subpersonal inferences do not work as they should, then the perceptual beliefs I form on the basis of the illegitimately generated experiences should also not come out as justified. Of course I do not think these considerations will be able to convince strong internalist foundationalists to change their view, but they do provide us with a reason to examine other candidates of foundationalism that could provide a better picture of perceptual justification when combined with PP.

\subsection{Weak internalist foundationalism}

A weaker form of internalist foundationalism can be found in works by Siegel (2012, 2013, 2017a,b). ${ }^{17}$ According to Siegel, perceptual experiences can be epistemically downgraded by their etiologies. In such cases the experience has less justificatory power than it would ordinarily have because of the way the experience is produced. For this to happen, it's crucial that the etiology in question is rationally assessable rather than merely a-rational, where the latter etiology only occurs in cases sufficiently similar to cases of belief-formation where "[...] we would not regard either ourselves or any of our subpersonal systems as convicted of any error if we ended up with those beliefs via that kind of process [...]" (Siegel 2013, p. 713). A-rational etiologies are thus connected to what one might call brute interventions on beliefs or experiences, whereas rationally assessable etiologies are connected to inferential transitions between contentful states.

According to Siegel, experiences with rationally assessable etiologies are epistemically downgraded when they have an etiology that is "sufficiently similar" (Siegel 2013 , p. 716) to a belief-etiology that would give rise to an unjustified belief. In her latest work (2017b), Siegel specifies that this similarity consists in experiences' being literally the result of the same type of bad inferences as beliefs, such as starting from epistemically inappropriate inferential inputs or jumping to conclusions. ${ }^{18}$ An example would be a variant of the earlier mentioned case of Jill and Jack, where Jill fears that Jack is angry and thereby jumps to the conclusion that Jack is angry on the basis of his blank stare. Forming the belief that Jack is angry on the basis of Jack's blank stare is just as epistemically bad as forming a perceptual experience with the content that Jack is angry on the basis of a (sub-)experience with the content that Jack has a blank stare. Both are instances of a bad type of inference, i.e., jumping to conclusions, and in both cases the role of fear appears similar: it somehow makes this inferential transition happen even though the premise does not fully support the conclusion.

\footnotetext{
17 Note, though, that Siegel does not explicitly endorse a version of foundationalism and might even prefer a version of coherentism.

18 This also allows Siegel to respond to worries about specifying in what way bad experience-etiologies are similar to bad belief-etiologies, and why exactly those etiologies are the ones that are epistemically bad (Vahid 2014; Lyons 2016b; Ghijsen 2016b).
} 
We can use this notion of experiential epistemic downgrade due to bad inference to make room for an epistemic role of PP's Bayesian inferences. If the Bayesian inferences are not performed properly, by, for instance, not updating priors correctly or simply ignoring some relevant hypotheses, then this could epistemically downgrade the perceptual experiences that are formed on their basis (assuming that similarly performed inferences with beliefs would lead to unjustified beliefs). Perceptual experience would, on this view, retain its ability to ground epistemically basic perceptual beliefs, but it would be prevented from justifying them when the previous Bayesian inferences were faulty.

Although the weaker form of internalist foundationalism thus seems to provide a more palatable combination with PP, it still leaves a crucial question unanswered. Why would Bayesian inferences only be able to undermine the justification provided by perceptual experience rather than also be able to empower experience to provide this justification in the first place $?^{19}$ That is, why would perceptual experience be the unjustified justifier in the chain of justification rather than another link which simply transmits this justification from the Bayesian inferences? This question appears especially pressing when one admits that rationally assessable etiologies have the power to undermine justification but rejects that such etiologies can also provide justification.

Siegel goes some way in accommodating this worry by not only allowing inferences to downgrade perceptual experiences, but also allowing them to upgrade perceptual experiences under the right conditions $(2017 \mathrm{~b}$, ch. 7). Even so, talk of downgrade and upgrade betray the thought that the baseline amount of justification provided by experience stems not from the inferences which gave rise to the experience, but from something present in the nature of experience itself. Indeed, Siegel is sympathetic to the idea that perceptual experiences have what she calls "positive epistemic charge" due to their presentational phenomenal character, the way in which experiences not only represent but also present their subjects with the way the world is. ${ }^{20}$ However, the relation between having a specific phenomenal character and having the power to justify subsequent beliefs seems unclear for reasons mentioned before: your perceptual experience presenting you with a specific state of affairs might make it reasonable to believe that that state of affairs is occurring, but that does not yet show that such a belief would also be justified. What's more, the motivation for connecting the epistemic status of experience to its etiology, namely, that there's more to being an epistemically proper experience than what might be accessible to the subject of that experience, actually counts against granting perceptual experience the power to provide baseline justification purely on the basis of its presentational phenomenal character. So the idea that perceptual experiences provide a baseline amount of justification that can only be modulated up or down by the quality of the preceding inferences looks like an unhappy marriage of two diverging intuitions about justification.

\footnotetext{
19 Also see Ghijsen (2016b) for a slightly different take on this problem.

20 The idea that the specific phenomenal character of perceptual experience is responsible for its power to justify can also be found in the works of many other internalist foundationalists (e.g., Tolhurst 1998; Huemer 2001; Pryor 2004; Tucker 2010; Chudnoff 2012; Bengson 2015). For discussion, see Ghijsen (2014).
} 
So perhaps we should look at an even weaker form of internalist foundationalism that ascribes the source of justification for epistemically basic beliefs to the priors and likelihoods on the basis of which perceptual experiences are formed according to PP. ${ }^{21}$ Although we could still count this as a form of internalism on the grounds that the relevant factors for justification are still part of a subject's mental states [along the lines of Feldman and Conee (2001)], it would become more difficult to see what would be left of the foundationalism. Certainly not just any prior, for instance, will count as a proper foundation for perceptual experience and belief. A crucial part of PP's proposal is that these priors are shaped in response to sensory input, prediction, and prediction-error, so it is only after this process of shaping and calibration has taken place that they can start to give rise to justified experiences and beliefs. What's more, even if one is reluctant to treat these priors as beliefs, perhaps they could still be shaped by such beliefs. In that case, the whole idea that there are such things as epistemically basic beliefs would become endangered.

In effect, it seems as if this final type of weak internalist foundationalism will have to construe justification as a property that emerges once a certain proper set of priors and beliefs is already in place, and so it would become more of a coherentist rather than foundationalist view. But this still would not answer our earlier worries about coherentism: not just any coherent set of priors and beliefs will do for justification, it will need to be a set that is directed at reflecting how the world actually is. Although the processes described by PP might take care of this worry, that is no part of a coherentist view of justification. Perhaps what is needed is thus an externalist element in our account of perceptual justification to link PP's empirical updating to how the world actually is. This is the topic for our next section.

\section{An externalist foundationalist answer}

\subsection{Inferentialist strong reliabilism}

According to an externalist foundationalist account of perception, perceptual beliefs derive their justification from being the output of a reliable process rather than from being supported by other beliefs. I will here focus on the account provided by Lyons (2009, 2016a), as this is a nicely developed externalist account with regard to the differences between basic and non-basic beliefs and conscious and unconscious evidence. Although Lyons labels his account 'inferentialist reliabilism', for reasons that will become clear I will label it here as an inferentialist strong reliabilism.

According to Lyons, a belief is epistemically basic if and only if its prima facie justification does not evidentially depend on other beliefs, i.e., if it is not based on other beliefs (Lyons 2009, p. 14). Such basic beliefs derive their justification, roughly, from being the output of a reliable non-inferential process carried out by a specific sort of cognitive system (Lyons 2009, p. 177). Non-basic beliefs, in contrast, require that the beliefs on which they evidentially depend are justified and that the inferential processes from which they stem are conditionally reliable (i.e., that they have a high

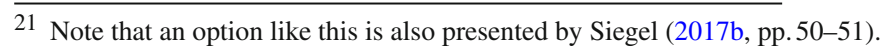


truth-ratio given that the input beliefs are true). Note that these different conditions for justification are actually part and parcel of any foundationalist view: given the distinction between basic and non-basic belief, it's no wonder that their source of justification will be different. However, Lyons' reliabilism is still exceptional in its explicit focus on the differing conditions, and it's the reason for calling the view inferentialist reliabilism.

Once we apply these ideas to perception, we arrive at the result that perceptual beliefs are basic because they are the output of a specific type of perceptual system, and that they are justified because the belief-forming processes of this system are non-inferential and reliable. However, if PP is correct, then it is no longer clear that the relevant perceptual processes are non-inferential in the sense that their outputs do not evidentially depend on further beliefs. Perceptual processing is performed on the basis of empirically derived priors, and even if one would not want to identify these priors with beliefs, then we could still question whether there is not still a relevant form of evidential dependence present here. Again, such a form of evidential dependence between purported basic beliefs and subpersonal priors would seriously undermine one of the key motivations for foundationalism, i.e., its answer to the epistemic regress problem.

Lyons' response to this worry is that only beliefs of the agent can be evidentially relevant (Lyons 2016a, p. 249). As noted before, the priors in PP appear to belong to subpersonal mechanisms and should not be identified with beliefs that are had by the agent herself. $^{22}$ The fact that subpersonal priors thus do not play any evidential role on Lyons' account, even though agent-level beliefs can play such an evidential role, is my reason for calling this view an inferentialist strong reliabilism.

Of course, we would like to have a principled reason for holding that subpersonal priors cannot play any evidential role, otherwise the inferentialist strong reliabilist account will not have fully addressed the worries raised by PP. ${ }^{23}$ According to Lyons, there is at least an indication that subpersonal priors do not play an evidential role in light of the fact that their epistemic status appears to be irrelevant to the epistemic status of the agent's perceptual beliefs:

The normal human visual system, for example, operates on several assumptions [or priors], including that nearby objects are lit from above, and that retinally adjacent points are probably roughly equidistant from the perceiver. An ordinary agent, who isn't versed in the principles of perceptual psychology, might well have very good reason to doubt such claims about light sources or retinal

\footnotetext{
22 Note that Lyons' distinction between personal-level and subpersonal beliefs need not map neatly onto the distinction between either conscious and unconscious or accessible and inaccessible beliefs. Unconscious and inaccessible beliefs might still be personal-level. For examples, see Lyons (2016a, p. 247 and pp. 252253).

23 Couldn't Lyons address this worry by simply maintaining that PP is at best seen as a model of perceptual functioning rather than a realistic description of what is going on at the implementational level (compare the strong internalist foundationalist response voiced in Sect. 3.1). Perhaps, but (a) it's not clear to me that such a model couldn't be used exactly to determine whether a belief is justified and, if not, why it isn't, and (b) a similar view should then be used to address paradigm cases of inference (are all of the beliefs really being used as premises to reach the conclusion at the implementational level?), which would make it doubtful that much inferentialism would remain of Lyons' inferentialist reliabilism.
} 
adjacency, rendering these beliefs or assumptions unjustified. But this wouldn't threaten the justification of her perceptual beliefs, at least not so long as she was unaware of how such assumptions are causally relevant to things looking the way they do. But if a belief/assumption's being unjustified doesn't detract from the justification of beliefs that causally depend on it, then the assumption isn't serving as evidence for those beliefs.

(Lyons 2016a, p. 249)

Assuming that Lyons is correct in his criterion for deciding when an assumption is not serving as evidence for a belief, then his conclusion is still not watertight. The fact that an agent has good reason to doubt claims about light sources or retinal adjacency does not immediately show that the visual system's priors about light sources or retinal adjacency are unjustified. After all, these priors have incorporated information from innumerable other occasions, and could remain justified in the face of the agent's personal-level contrary reasons. Indeed, if we genuinely want to distinguish between subpersonal assumptions and personal-level beliefs, then we should also be careful not to conflate their possible conditions for justification. If that's correct, then the example simply does not show that subpersonal priors do not evidentially justify perceptual beliefs.

As a sidenote, a similar point can be made about Lyons' contention that the assumptions responsible for implicit bias should be seen as introspectively inaccessible personal-level beliefs rather than as subpersonal assumptions of perceptual systems. A crucial difference between the assumptions relevant for bias and the assumptions of the visual system is supposedly related to the way in which these are acquired:

Simply hearing my drunken, racist uncle spout nonsense about the location of light sources-even thousands of times-won't affect my visual system's assessments of convexity. But if his nonsense is about ethnic groups, it can have an effect on me, despite my better judgment.

(Lyons 2016a, p. 253)

Again, though, even if the drunken uncle is spouting nonsense about the location of light sources thousands of times, the visual system also has access to tons of perceptual evidence about the location of light sources that is in conflict with the testimonial nonsense. The example thus does not show that testimony can never impact priors within the perceptual hierarchy, and, indeed, one might claim that implicit bias is exactly a case where testimony is able to influence these priors. Perhaps it is true that, say, some job applicants are literally perceived as less qualified because of implicit bias. That is still an open question, and one that might be answered affirmatively if PP is on the right track.

Nevertheless, Lyons is surely right in his observation that, in general, there is a difference in the way the visual system arrives at its subpersonal priors and the way in which we arrive at our personal-level beliefs (Lyons 2016a, p. 250). Our personal-level beliefs can be swiftly altered in the light of only one new piece of information, whereas the priors of the visual system are updated far more slowly on the basis of accumulated prediction errors. This means that even if I receive very strong testimony about, say, the 
location of light sources, this will never have an immediate impact on the priors of my visual system. This what we may call "weak informational encapsulation" of the visual system appears sufficient to distinguish belief-acquisition via the perceptual system from belief-acquisition via inference on the basis of other personal-level beliefs. But the question is whether the weak informational encapsulation of this belief-forming process is also sufficient to count its output-beliefs as epistemically basic.

Weak informational encapsulation at least makes plausible that our perceptual beliefs do not evidentially depend on our other personal-level beliefs. Personal-level beliefs impact perceptual beliefs only via slow changes in the perceptual hierarchy, and this makes it plausible that the perceptual beliefs are not based on the personal-level beliefs. ${ }^{24}$ But this still leaves open whether perceptual beliefs are based on subpersonal priors of the perceptual system. Although this possibility again seems to put pressure on the key motivation for foundationalism, i.e., its solution to the epistemic regress problem, there might be a way to respond to this worry. In the final section of this paper I will sketch an externalist foundationalist view that would allow an evidential role for subpersonal priors without leading to an infinite epistemic regress.

\subsection{Inferentialist weak reliabilism}

Where on the earlier inferentialist strong reliabilism, perceptual beliefs were nonevidentially justified by being the output of a reliable perceptual process, an inferentialist weak reliabilism will hold that subpersonal priors themselves are non-evidentially justified by being acquired in a reliable way. This will allow the inferentialist weak reliabilist to assign an evidential role to subpersonal priors without falling prey to an epistemic regress problem. Note immediately that this inferentialist weak reliabilism will have a crucial virtue over the earlier discussed weak internalist foundationalism: it will be able to ground the types of priors capable of providing evidential justification by linking their own justification to an externalist clause (such as being reliably acquired). So, unlike the weak internalist foundationalist, who only had recourse to something like coherence to justify priors, the inferentialist weak reliabilist can appeal to the prior's connection to the world to explain its justificatory status. We thus have a truly foundationalist answer to the epistemic regress problem, although the foundation will plausibly consist out of a large interconnected set of subpersonal priors rather than a couple of special beliefs about the world.

To get a better grip on the differences between the two versions of inferentialist reliabilism, consider the following case. Suppose one's perceptual priors are influenced by biased media coverage, which depicts a certain social group as associated with violent crimes about $45 \%$ of the time, whereas members of this group are only responsible for $5 \%$ of violent crime. These influenced priors can plausibly lead one to perceive members of the relevant social group as dangerous, thereby leading one to believe that these members are in fact dangerous. On the sketched inferentialist weak reliabilism, one would have to look at how the relevant priors were acquired to determine whether

\footnotetext{
24 If such beliefs can be said to impact the hierarchy at all. Perhaps it's more accurate to say that the information on which the beliefs are based is having a slow impact on the perceptual hierarchy.
} 
the inferred perceptual experiences and beliefs would be justified. Assuming that the relevant process of prior-acquisition can be seen as unreliable (acquisition via a biased sample), the inferentialist weak reliabilism would give the verdict that the perceptual beliefs are unjustified. After all, given that the relevant priors here are unjustified, so would the subsequent experiences and beliefs based on those priors, given that this is a type of inferential justification.

In contrast, the inferentialist strong reliabilism would have to look at the perceptual process at work when one perceives a specific member of the wrongly depicted social group, and determine whether that process is unreliable. Here it is more difficult to argue on a principled basis that the relevant perceptual process type is unreliable; it certainly is not obvious that the process type should be taken as specific as being only about categorizing members of that specific social group as dangerous or not. Of course both versions of reliabilism will still need a principled way of specifying which precise process types are relevant to justification [Conee and Feldman's (1998) well-known Generality Problem for reliabilism] but at least the inferentialist weak reliabilist view might have an easier time by looking at the process of acquiring the relevant priors, whereas the inferentialist strong reliabilist view will have to look at the process that is operative when the priors are being put to use. ${ }^{25}$ It should be noted, though, that the process of acquiring priors might be more vague than the process of forming beliefs, as this will be a more temporally extended process: we should be looking at the influence of specific sorts of sensory input on multiple occasionseven if inferential processing will also be important on each of those occasions (with questions ranging from whether the data sets were not too idiosyncratic to whether the priors were updated in the right way). The inferentialist weak reliabilist view might thus get a better handle on some complex cases due to its focus on prior acquisition rather than the way they are exploited, though it will definitely need to say more about how to delineate such processes of acquisition.

Another consideration in favor of an inferentialist weak reliabilism has to do with drawing a principled line between those entities that are evidentially relevant and those that are not. We already saw that it is difficult to find a principled reason to hold that only agent-level beliefs, in contrast to subpersonal priors, can be evidentially relevant for further beliefs. Although Lyons does present a weak indication that the subpersonal is evidentially irrelevant (Sect. 4.1), what we would like is an explanation of why this is so. We might have a better chance of providing such an explanation if we draw the line of evidential significance at the level of subpersonal priors. These are the mental entities at the beginning of inference, so this is where we should draw the line between evidential relevance and non-evidential relevance. The extra-mental processes whose reliability will determine the justification of the priors themselves will then be those that are non-evidentially relevant.

One important worry here has to do with the fact that priors are themselves presumably generated and updated in response to innumerable encounters with sensory input,

\footnotetext{
25 Couldn't the inferentialist strong reliabilist point at the inaccuracy of the priors to explain why the relevant perceptual process is unreliable? Perhaps, but there could also be cases with accurate but unreliably acquired priors, e.g., when one comes across unreliable information that nevertheless gets it right. See Vaassen (2016, pp. 10-11) for a case that could be developed in this direction.
} 
perhaps starting with some that are simply innately specified. So shouldn't the chain of evidential justification then continue on from one's current priors to those that got the updating-process going from the get-go? That need not be the case: whenever a perceptual belief is formed, the inferential process will simply terminate at the set of priors that are present and relevant at that time. ${ }^{26}$ This is so even if those priors would not be justified if earlier priors hadn't been justified.

To see this, compare the case of memorial beliefs. I might now remember that $q$ because I long ago deduced it from another belief that $p$ and a belief that if $p$, then $q$. If by now I have long forgotten about those other beliefs, then the memorial belief that $q$ should no longer be construed as being evidentially based on them. Yet whether the retained belief was originally justified, and whether the original inference was a good one, still appears relevant to the justification of the memorial belief. So there are cases where historical facts about the justification of earlier beliefs matter for the justificatory status of one's current beliefs, even though the current beliefs are no longer evidentially based on those earlier beliefs. The same could be true for subpersonal priors: how they came about is certainly relevant for determining their justification, but this etiology need not itself be a further evidential factor that supports perceptual belief. By taking this route one can maintain that there is an evidential foundation in perception, even if this foundation is to be found at a deeper (subpersonal) level than originally expected.

\section{Conclusion}

I have explored several ways in which one is able to maintain a foundationalist account of perception in the face of the challenge from predictive processing. On a strong internalist foundationalist account, one should simply ignore subpersonal processes, and focus only on the content and phenomenology of experience to determine whether a belief is epistemically basic and prima facie justified. The challenge for this view is to explain why subpersonal inferences of the sort posited by PP are irrelevant to the epistemic status of experience itself. On a weaker form of internalist foundationalism, one can either accept that subpersonal processes can merely diminish perceptual justification when such processes are faulty, or else accept that subpersonal processes are also relevant in determining whether experience itself is justified. The former view leaves unexplained why subpersonal processes could only be relevant in diminishing perceptual justification rather than also providing a source for this justification, and the latter view cannot explain why only a specific set of subpersonal priors could account for perceptual justification (as foundationalism would maintain).

An externalist foundationalism appears to provide the best fit with PP, as it can easily acknowledge that subpersonal processes are also relevant in determining perceptual justification without positing an asymmetry between how that justification is produced and how it is diminished. However, the specific version of externalist foundationalism I have discussed, i.e., inferentialist reliabilism, will have to choose whether the epistemic foundation it envisages is constituted by reliably produced, personal-level perceptual

\footnotetext{
26 What if, as a referee notes, evidential dependence can be broader than just inferential dependence? This seems not only problematic for this specific response to the worry, but also for foundationalism in general.
} 
beliefs or by reliably acquired subpersonal priors. The former strong account will need a principled reason for holding that only personal-level beliefs can be evidentially relevant, and it is exactly at this point that the latter weak account seems better off: the evidential regress stops at the subpersonal priors as these are simply the mental starting points of inference. What's more, the inferentialist weak reliabilism might also provide a slightly better handle on the complex ways in which perceptual justification could be affected by etiology, as it immediately directs attention to how certain perceptual priors are acquired.

Acknowledgements This paper was presented at the 2017 Perception and Justified Belief Workshop at Ruhr-Universität Bochum, the 2017 Bled Philosophical Conference on Epistemic Virtues and Epistemic Skills and the OZSW Research Seminar for Analytic Philosophy. Thanks to the audiences at these events for their helpful feedback. Also thanks to Daphne Brandenburg, Marc Slors, Leon de Bruin and other members of the Cognition, Culture and Language group at Radboud University for their feedback to this paper. Special thanks to Jack Lyons and two anonymous referees for their critical comments and suggestions to an earlier draft of this paper.

Open Access This article is distributed under the terms of the Creative Commons Attribution 4.0 International License (http://creativecommons.org/licenses/by/4.0/), which permits unrestricted use, distribution, and reproduction in any medium, provided you give appropriate credit to the original author(s) and the source, provide a link to the Creative Commons license, and indicate if changes were made.

\section{References}

Alston, W. P. (1988). An internalist externalism. Synthese, 74(3), 265-283.

Bengson, J. (2015). The intellectual given. Mind, 124, 707-760.

BonJour, L. (1985). The structure of empirical knowledge. Cambridge, MA: Harvard University Press.

Bruineberg, J., Kiverstein, J., \& Rietveld, E. (2016). The anticipating brain is not a scientist: The freeenergy principle from an ecological-enactive perspective. Synthese (online first). https://doi.org/10. 1007/s11229-016-1239-1.

Chudnoff, E. (2011). The nature of intuitive justification. Philosophical Studies, 153, 313-33.

Chudnoff, E. (2012). Presentational phenomenology. In S. Miguens \& G. Preyer (Eds.), Consciousness and subjectivity (pp. 51-72). Frankfurt: Ontos Verlag.

Clark, A. (2013). Whatever next? Predictive brains, situated agents, and the future of cognitive science. Behavioral and Brain Sciences, 36(3), 181-204.

Clark, A. (2016). Surfing uncertainty: Prediction, action, and the embodied mind. Oxford: Oxford University Press.

Conee, E., \& Feldman, R. (1998). The generality problem for reliabilism. Philosophical Studies, 89(1), $1-29$.

Feldman, R., \& Conee, E. (2001). Internalism defended. American Philosophical Quarterly, 38(1), 1-18.

Friston, K. (2009). The free-energy principle: A rough guide to the brain? Trends in cognitive sciences, 13(7), 293-301.

Friston, K. (2010). The free-energy principle: A unified brain theory? Nature Reviews Neuroscience, 11(2), $127-138$.

Fumerton, R. (2013). Siegel on the epistemic impact of "checkered" experience. Philosophical Studies, 162(3), 733-739.

Ghijsen, H. (2014). Phenomenalist dogmatist experientialism and the distinctiveness problem. Synthese, 191(7), 1549-1566.

Ghijsen, H. (2016a). The puzzle of perceptual justification. New York: Springer.

Ghijsen, H. (2016b). The real epistemic problem of cognitive penetration. Philosophical Studies, 173(6), $1457-1475$.

Hohwy, J. (2013). The predictive mind. Oxford: Oxford University Press.

Huemer, M. (2001). Skepticism and the veil of perception. Lanham, MD: Rowman \& Littlefield Publishers. 
Huemer, M. (2013). Epistemological asymmetries between belief and experience. Philosophical Studies, 162(3), 741-748.

Jackson, A. (2011). Appearances, rationality, and justified belief. Philosophy and Phenomenological Research, 82(3), 564-593.

Klein, P. D. (1999). Human knowledge and the infinite regress of reasons. Philosophical Perspectives, 13, 297-325.

Kvanvig, J. (1995). Coherentists' distractions. Philosophical Topics, 23(1), 257-274.

Lyons, J. (2009). Perception and basic beliefs: Zombies, modules and the problem of the external world. Oxford: Oxford University Press.

Lyons, J. (2011). Circularity, reliability, and the cognitive penetrability of perception. Philosophical Issues, 21(1), 289-311.

Lyons, J. (2016a). Unconscious evidence. Philosophical Issues, 26(1), 243-262.

Lyons, J. C. (2016b). Inferentialism and cognitive penetration of perception. Episteme, 13(1), 1-28.

Macpherson, F. (2017). The relationship between cognitive penetration and predictive coding. Consciousness and Cognition, 47, 6-16.

Markie, P. (2013). Searching for true dogmatism. In C. Tucker (Ed.), Seemings and justification: New essays on dogmatism and phenomenal conservatism (pp. 248-269). Oxford: Oxford University Press.

McGrath, M. (2013). Siegel and the impact for epistemological internalism. Philosophical Studies, 162(3), $723-732$.

Peijnenburg, J., \& Atkinson, D. (2013). The emergence of justification. Philosophical Quarterly, 63(252), 546-564.

Pryor, J. (2000). The skeptic and the dogmatist. Noûs, 34(4), 517-549.

Pryor, J. (2004). What's wrong with moore's argument? Philosophical Issues, 14, 349-78.

Siegel, S. (2012). Cognitive penetrability and perceptual justification. Noûs, 46, 201-22.

Siegel, S. (2013). The epistemic impact of the etiology of experience. Philosophical Studies, 162(3), 697722.

Siegel, S. (2017a). How is wishful seeing like wishful thinking? Philosophy and Phenomenological Research, 95(2), 408-35.

Siegel, S. (2017b). The Rationality of Perception. Oxford: Oxford University Press.

Seriés, P., \& Seitz, A. (2013). Learning what to expect (in visual perception). Frontiers in Human Neuroscience, 7, 668.

Tolhurst, W. (1998). Seemings. American Philosophical Quarterly, 35(3), 293-302.

Tucker, C. (2010). Why open-minded people should endorse dogmatism. Philosophical Perspectives, 24(1), $529-545$.

Tucker, C. (2013a). Seemings and justification: An introduction. In C. Tucker (Ed.), Seemings and justification: New essays on dogmatism and phenomenal conservatism (pp. 1-29). Oxford: Oxford University Press.

Tucker, C. (Ed.). (2013b). Seemings and justification: New essays on dogmatism and phenomenal conservatism. Oxford: Oxford University Press.

Vaassen, B. M. K. (2016). Basic beliefs and the perceptual learning problem: A substantial challenge for moderate foundationalism. Episteme, 13(1), 133-149.

Vahid, H. (2014). Cognitive penetration, the downgrade principle, and extended cognition. Philosophical Issues, 24(1), 439-459.

Varga, S. (2017). Perceptual experience and cognitive penetrability. European Journal of Philosophy, 25(2), 376-97. 